\title{
A CONCORRÊNCIA, O CONCORRENTE E O CONSUMIDOR: A ACÇÃO CIVIL POR VIOLAÇÃO DE NORMAS DE DEFESA DA CONCORRÊNCIA ${ }^{1}$
}

\author{
Célia Ferreira Matias ${ }^{2}$
}

\begin{abstract}
"competition Much honoured in the breach. Businessmen have been known to recommend it for others whilst pleading an acute cardiac condition precluding their taking part in the exercise themselves."
\end{abstract}

Nicholas Von Hoffman, A Devil's Dictionary of Business, Nation Books, New York, 2005

\section{INTRODUÇÃO}

Num estudo de 2005, assinado por três autores, entre os quais o Nobel da economia, Douglas North $^{3}$, a livre concorrência e, em particular, a livre entrada no mercado, é vista como o factor que permite a uma sociedade evoluir daquilo a que os autores chamam "Estado natural" para uma sociedade economicamente desenvolvida. A economia das sociedades em que existem bloqueios à concorrência encontra-se num estado de não desenvolvimento, enquanto não forem retirados os bloqueios. Por isso, afirmam, onde não há

\footnotetext{
${ }^{1}$ Trabalho realizado no âmbito do Curso de Pós-Graduação em Direito das Empresas do IDET - Instituto de Direito das Empresas e do Trabalho / Faculdade de Direito da Universidade de Coimbra - ano lectivo 2007/2008

${ }^{2}$ A autora é licenciada em direito pela Faculdade de Direito da Universidade de Lisboa e tem um curso de Pós-Graduação em Direito das Empresas pela Faculdade de Direito da Universidade de Coimbra. É advogada na sociedade de advogados Miranda, Correia, Amendoeira e Associados.

E-mail: celia.matias@mirandalawfirm.com

${ }^{3}$ Douglass C. North, John Joseph Wallis, and Barry R. Weingast, The Natural State:The Political-Economy Of Non-Development, March 2005. Texto integral disponível em: http://www.fnf.org.ph/downloadables/Douglass\%20North\%20Article.pdf
}

Revista Brasileira de Direito Internacional, Curitiba, v.7, n.7, jan./jun.2008 
concorrência, não há desenvolvimento, pelo que a expressão "país em vias de desenvolvimento" é um conceito vazio.

É por se reconhecer a importância da concorrência para a economia e para a sociedade que muitos Estados, como os Estados Unidos da América ("EUA") e os países da União Europeia (“UE"), tomaram medidas legislativas para proteger a concorrência, proibindo os comportamentos que a falseiam.

Mas tão importante é prever uma interdição como os meios de a tornar efectiva. Em Portugal, aquando da criação da Autoridade da Concorrência ("AdC"), foi equacionada a previsão de sanções criminais a par das sanções de natureza contra-ordenacional que acabaram por ficar consagradas ${ }^{45}$. Mas a solução criminal está presente noutros ordenamentos jurídicos, como o do Reino Unido, onde a aplicação de penas privativas da liberdade para as pessoas físicas que sejam agentes deste tipo de crime se tornou uma realidade, após a publicação, em 2002, do Enterprise Act ${ }^{6}$. Por cá, as empresas infractoras são punidas com coimas aplicadas pela AdC, que têm por base o volume de negócios da infractora, entre outros factores como a gravidade e o grau de participação, permitindo assim a aplicação de sanções mais talhadas às características da entidade que se pretende punir.

Até agora vimos apenas sanções que visam proteger a concorrência como modo saudável de funcionamento do mercado, incutindo nos potenciais infractores temor de sofrer sanções pesadas sobre o seu património e, como vimos, eventualmente, sobre a sua pessoa. No domínio da prevenção, o pagamento de uma indemnização pode também produzir um significativo efeito dissuasor. Tal depende do grau de facilidade com que os particulares possam recorrer aos tribunais com esta finalidade, das tendências jurisprudenciais, que

\footnotetext{
${ }^{4}$ Conforme a "Proposta de Plano de Trabalhos (Documento Preliminar)" citada a pp. 22 e 23 de Concorrência, Estudos, Coordenação de António Goucha Soares e Maria Manuel Leitão Marques, Almedina, 2006.

${ }^{5} \mathrm{Na}$ doutrina norte-americana, Posner defende a aplicação de penas de natureza pecuniária em detrimento de penas privativas da liberdade, afirmando que a finalidade das sanções no domínio antitrust consiste em devolver os custos sociais da violação ao violador ("to place the social costs of the violation on the violator"). Richard A. Posner, Antitrust Law, Second Edition, The University of Chicago Press, Chicago and London, p. 296.

${ }^{6}$ A primeira condenação ao abrigo destas disposições teve lugar a 11 de Junho de 2008: Executives jailed in marine hose cartel case, Melvyn Howe, Press Association, in The Guardian, Thursday June 12 2008:

http://www.guardian.co.uk/business/2008/jun/12/corporatefraud.ukcrime
}

Revista Brasileira de Direito Internacional, Curitiba, v.7, n.7, jan./jun.2008 
tornam mais ou menos frequente a condenação e das quantias que possam ser obtidas. A própria AdC admite a importância dissuasora do private enforcement, em parecer enviado à Comissão Europeia, no âmbito da consulta pública subsequente à publicação do recente Livro Branco sobre Acções de Indemnização por Incumprimento das Regras Comunitárias no Domínio Antitrust". Para além disso, o private enforecement contribui para "o desenvolvimento de uma cultura de concorrência e para o conhecimento das suas regras, e, em especial, a sua utilidade no preenchimentos das lacunas derivadas do facto de a Comissão e as autoridades da concorrência nacionais não terem tempo nem recursos para lidar com todas as condutas anticoncorrenciais"8.

No entanto, a verdadeira razão de ser das sanções civis é o ressarcimento de alguém. Por isso, em qualquer sistema jurídico, o pressuposto fundamental da responsabilidade civil é o dano. Assim, não fará grande sentido falar em sanções civis se não identificarmos situações em que a violação do direito da concorrência prejudique alguém em concreto, e já não apenas a "concorrência" em abstracto. Esse alguém pode ser outra empresa do mesmo mercado, uma empresa economicamente dependente da infractora, ou simplesmente o consumidor que se vê obrigado a pagar mais por produtos cujo preço seria inferior, não fosse, por exemplo, pela existência de um acordo secreto entre empresas que decidiram praticar preços mais altos. A temática do private enforcement faz, desta forma, a ponte entre a defesa da concorrência e a defesa do concorrente e do consumidor.

Num primeiro capítulo, percorremos brevemente a evolução histórica da figura e os contornos que tem adquirido em alguns sistemas jurídicos em que já conheceu aplicação prática ou análise doutrinal. De seguida, analisamos as normas actualmente vigentes que podem ser convocadas para traçar um

7 "A AdC reconhece a importância que o "private enforcement" é susceptível de assumir enquanto um dos pilares de "enforcement" do Direito da Concorrência em geral. Para além da função reparatória que por definição lhe cabe, pode desempenhar um importante papel de difusão da cultura de concorrência e de dissuasão de infracções futuras, essencial para a afirmação de mercados mais eficientes do ponto de vista concorrencial." Texto completo em : http://ec.europa.eu/comm/competition/antitrust/actionsdamages/white_paper_comments/acport pt.pdf

${ }^{8}$ Sara Estima Martins, NewsLexter, PLMJ, Abril de 2006. Pode ser encontrado no site da sociedade de advogados: www.plmj.com

Revista Brasileira de Direito Internacional, Curitiba, v.7, n.7, jan./jun.2008 
regime jurídico da responsabilidade civil por violação de normas de direito da concorrência em Portugal. Por fim, observamos os traços de evolução que actualmente se desenham, tendo em atenção os seus pontos fortes e as matérias ainda nebulosas ou sensíveis. 


\section{PRIVATE ENFORCEMENT - RESENHA HISTÓRICA E COMPARATÍSTICA.}

O presente capítulo é encabeçado por uma expressão inglesa porque visa enquadrar o private enforcement no tempo e no espaço, bem como procurar nas origens da figura e na sua evolução um significado a que nos possamos ater ao longo da análise que se segue.

Do ponto de vista do direito comparado, dois pilares devem ser considerados: o ordenamento jurídico dos Estados Unidos e a ordem jurídica comunitária. No entanto, outros sistemas podem trazer importantes contributos para a discussão, nomeadamente, determinados países da Europa, como o Reino Unido.

Comecemos então pelos Estados Unidos. O artigo 4 do Clayton Act prevê expressamente a reparação dos danos sofridos por qualquer pessoa, no seu negócio ou património, em resultado de qualquer conduta contrária às leis antitrust. Mas a lei vai ainda mais longe, estabelecendo uma indemnização de carácter punitivo de três vezes o montante dos danos. Acrescem custos, honorários e juros. Para além disso, não está prevista uma cláusula de "quem perde paga" relativamente às custas, pelo que a propositura de acções não encontra nesse factor um desincentivo, tal como acontece noutros sistemas jurídicos, como o português.

Apesar de o Clayton Act remontar ao início do século XX, foi na década de 60 que a litigância privada no âmbito do direito da concorrência conheceu o seu maior incremento, fruto de uma vaga de condenações em sede criminal, que foram aproveitadas pelos particulares; da jurisprudência favorável do Supremo Tribunal; da possibilidade de obter treble damages (a multiplicação dos danos por 3, acima referida); e de ser julgado por um tribunal de júri. Isto levava frequentemente os réus a celebrarem acordos desvantajosos, pois não podiam prever qual seria a decisão de um júri cujos membros, com grande probabilidade, não teriam quaisquer conhecimentos de direito ou de 
concorrência ${ }^{9}$. Daí as críticas feitas ao sistema, por este ser susceptível de potenciar o oportunismo de quem busca apenas extorquir um bom settlement ${ }^{10}$.

Esta tendência expansionista inverteu-se no final da década seguinte, em resultado de uma inversão da jurisprudência do Supremo Tribunal, quer no plano substantivo, quer no plano processual, por exemplo, com a limitação da legitimidade para recorrer aos tribunais federais e com a inatendibilidade da prova circunstancial.

Outras características do regime norte-americano são a presunção de ilegalidade em caso de confissão ou condenação em processo crime pelos mesmos factos, a possibilidade de class actions e o regime da clemência, segundo o qual os participantes vêem a sua responsabilidade limitada aos danos efectivamente sofridos pelo autor (e não em triplicado). Actualmente, o sistema instituído pelo Clayton Act e testado na prática ao longo de várias décadas persiste, não sendo, porém, isento de críticas ou ensejos reformistas vindas dos seus próprios intervenientes.

$\mathrm{Na}$ União Europeia, o desenvolvimento do direito da concorrência foi algo mais tardio e, por isso, também a evolução para um sistema de private enforcement demorou a dar sinais. Para tal contribuiu a menor "cultura litigante" nas jurisdições europeias, onde, tradicionalmente, não há tribunal de júri em matéria civil nem indemnizações punitivas e onde a quota litis é proibida, por ser atentatória da dignidade da profissão.

Esta matéria encontra-se consagrada nos artigos $81 .{ }^{\circ}$ e $82 . .0$ do Tratado de Roma ("TCE"). Poder-se-á dizer, portanto, que esta matéria faz parte da constituição económica da UE (recorrendo a terminologia tudo menos incontroversa). $\mathrm{O}$ artigo 81.-. versa sobre acordos entre empresas, decisões de associações de empresas e práticas concertadas susceptíveis de impedir, restringir ou falsear a concorrência no mercado comum, considerando-os nulos.

\footnotetext{
${ }^{9}$ Kevin E. Grady, Lessons learned from the US experience in private enforcement of competition law, Handbook of Research in Trans-Atlantic Antitrust, Edward Elgar, 2006.

${ }^{10}$ Comments of the Section of Antitrust Law and the Section of International Law of the American Bar Association in Response to the Request for Public Comment of the Commission of the European Communities On Damage Actions for Breaches of EU Antitrust Rules, April 2006, p. 4 . 4 Texto disponível em: http://ec.europa.eu/comm/competition/antitrust/actionsdamages/files_green_paper_comments/a ba.pdf
}

Revista Brasileira de Direito Internacional, Curitiba, v.7, n.7, jan.jun.2008 
O artigo $82 .^{\circ}$ proíbe, na medida em que tal seja susceptível de afectar o comércio entre os Estados Membros, o facto de uma ou mais empresas explorarem de forma abusiva uma posição dominante no mercado comum ou numa parte substancial deste.

O Conselho veio, logo em 1962, legislar sobre a aplicação destas disposições. Posteriormente, esse primeiro Regulamento viria a ser substituído pelo Regulamento (CE) N. $\stackrel{0}{1 / 2003}$ do Conselho, de 16 de Dezembro de 2002, em que se incluem disposições de carácter processual, por exemplo, sobre ónus da prova, a investigação e a cooperação entre entidades comunitárias e nacionais. As sanções previstas no Regulamento são de carácter público: coimas e sanções pecuniárias compulsórias. Porém, o artigo $6 .^{\circ}$ abre as portas à acção privada, ao estabelecer que os tribunais nacionais têm competência para aplicar os artigos $81 .^{\circ}$ e $82 .^{\circ}$ do Tratado. De notar que sempre que estejam em causa situações susceptíveis de afectar o comércio entre os Estados-Membros, os tribunais nacionais devem aplicar apenas o direito comunitário, sendo nos demais casos aplicáveis as normas internas de direito da concorrência. Várias questões de direito comunitário da concorrência podem assim chegar aos tribunais dos Estados-Membros: a nulidade de acordos ou decisões proibidas, a responsabilidade contratual no âmbito de um tal acordo, medidas cautelares e a responsabilidade civil extra-contratual para o ressarcimento de danos devidos a violações de regras antitrust ${ }^{1112}$. No presente estudo, analisaremos apenas a última questão.

O Tribunal de Justiça das Comunidades Europeias ("TJCE") tem sido um dos principais motores do desenvolvimento do direito comunitário. Também no que diz respeito à questão que nos ocupa, a sua posição tem sido fundamental, em acórdãos como Courage v, Creham $^{13}$, ou Manfredi v. Lloyd Adriatico Assicurazioni ${ }^{14}$.

\footnotetext{
11 António Goucha Soares, A Aplicação Descentralizada das Normas Comunitárias da

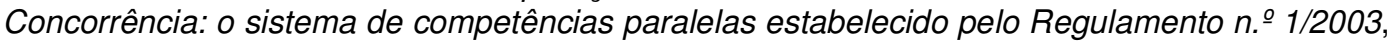
pp. 189 e 193, in Concorrência, Estudos, Coordenação de António Goucha Soares e Maria Manuel Leitão Marques, Almedina, 2006.

${ }^{12}$ Sara Estima Martins, NewsLexter, PLMJ, Abril de 2006. Pode ser encontrado no site da sociedade de advogados: www.plmj.com

${ }^{13}$ Texto disponível em:
}

Revista Brasileira de Direito Internacional, Curitiba, v.7, n.7, jan./jun.2008 
O Acórdão Courage v. Creham resultou de um conjunto de questões colocadas por um tribunal do Reino Unido ao TJCE. Convém lembrar que o ressarcimento de danos pela violação do direito da concorrência era já prática no sistema jurídico inglês, pelo que as questões colocadas ao TJCE assumem já esse pressuposto. O tribunal estava essencialmente preocupado com a legitimidade activa para o ressarcimento desses danos. No caso subjacente, Creham é arrendatário de um pub cuja sociedade proprietária é participada pela Courage, um fabricante de cerveja, sendo que do contrato faz parte uma clausula de "beer tie", ou seja, a obrigação de comprar cerveja à Courage, obedecendo a mínimos por esta imposta e a preços alegadamente superiores aos praticados pela mesma empresa ao contratar com estabelecimentos independentes. Ao ser demandado em tribunal por incumprimento da obrigação de pagar a cerveja fornecida, Creham defende-se alegando o carácter restritivo da concorrência do contrato em que é parte e pedindo, por sua vez, uma indemnização pelos danos que o mesmo contrato lhe causou. Perante a disposição nacional que impede o participante num acordo anti-concorrencial de ser ressarcido, o tribunal inglês recorreu ao TJCE para dissipar a dúvida à luz do direito comunitário, e do seu primado sobre o direito nacional. Dando de barato que concorrentes e consumidores lesados podem ver os seus danos ressarcidos, o TJCE veio admitir, ainda que limitadamente, o ressarcimento de danos por parte dos participantes no próprio acordo restritivo da concorrência.

Por sua vez, no Acórdão Manfredi v. Lloyd Adriatico Assicurazzioni, que teve por base um caso em disputa perante os tribunais italianos, o TJCE começa por se pronunciar sobre uma questão da competência dos tribunais nacionais para atribuir indemnizações por responsabilidade civil fundada na violação dos artigos $81 . .^{\circ}$ e 82. do TCE, concluindo pela admissibilidade, desde que se verifique um nexo de causalidade entre a violação do TCE e os danos invocados. No entanto, o regime da responsabilidade civil é remetido, na ausência de específicas normas comunitárias sobre o assunto, para os direitos

http://curia.europa.eu/jurisp/cgi-

$\mathrm{bin} /$ form.pl?lang=en\&Submit=Submit\&alldocs=alldocs\&docj=docj\&docop=docop\&docor=docor \& docjo $=$ docjo\&numaff $=\&$ datefs $=\&$ datefe $=\&$ nomusuel $=$ courage $\&$ domaine $=\& \operatorname{mots}=\&$ resmax $=100$

${ }^{14}$ Texto disponível em:

http://eur-lex.europa.eu/LexUriServ/LexUriServ.do?uri=OJ:C:2006:224:0003:0004:EN:PDF

Revista Brasileira de Direito Internacional, Curitiba, v.7, n.7, jan./jun.2008 
nacionais, respeitados que estejam os princípios da equivalência e da efectividade. Contam-se entre os aspectos remetidos para o direito nacional a noção de nexo de causalidade, o tribunal competente, o prazo de prescrição e a quantificação dos danos.

Ainda no plano do direito comunitário, há que assinalar os esforços da Comissão na promoção do debate sobre o private enforcement, primeiro através de um Livro Verde sobre acções de indemnização devido à violação de regras comunitárias no domínio antitrust (2005) e, mais recentemente, de um Livro Branco (2008), precedidos pelo Relatório Ashurst (2004), um estudo privado encomendado pela Comissão a essa sociedade de advogados.

Enquanto o Relatório Ashurst ${ }^{15}$ traça o diagnóstico ao private enforcement nos países da UE, o Livro Verde, publicado pela Comissão no ano seguinte, coloca uma série de questões sobre o seu regime concreto, com o objectivo de potenciar a efectividade deste mecanismo. Após um período de consulta, surge o Livro Branco sobre o mesmo tema, ele próprio sujeito a um período de consulta pública encerrada recentemente.

O cenário nos vários Estados da UE, tal como retratado no Relatório Ashurst mostra-se heterogéneo e sub-desenvolvido. À data, apenas 3 Estados dispunham de legislação específica e um pequeno número de casos deu origem a um número ainda mais pequeno de indemnizações efectivamente atribuídas. Por exemplo, no Reino Unido existe legislação específica, mas o número de casos decididos é baixo. Em França, não existindo legislação específica, existe um pequeno número de casos decididos. Outras jurisdições contam com uma igualmente reduzida experiência neste domínio, como a alemã, a irlandesa e a holandesa ${ }^{16}$.

Portugal não possui ainda experiência na aplicação privada do direito da concorrência. Enquanto membro da UE, Portugal tem um regime de direito da concorrência de carácter dúplice. Sempre que seja afectado o comércio entre Estados Membros, serão aplicáveis os artigos 81.ำ 82.ำ do TCE e, nos demais casos, as leis antitrust nacionais, nomeadamente a Lei 18/2003. Quer num caso quer noutro, as normas aplicáveis à acção de responsabilidade civil

\footnotetext{
${ }^{15} \mathrm{http}$ //ec.europa.eu/comm/competition/antitrust/actionsdamages/study.html

${ }^{16}$ Richard Whish, Competition Law, Fifth Edition, LexisNexis, UK, p. 302.
}

Revista Brasileira de Direito Internacional, Curitiba, v.7, n.7, jan./jun.2008 
são as de fonte nacional, uma vez que ainda não existe regime comunitário que se sobreponha àquelas. No entanto, no que toca à aplicação dos artigos $81 . \mathrm{e}$ 82. do TCE em sede de responsabilidade civil, existe já alguma pressão por parte de Bruxelas para que o regime seja agilizado, o que adiante veremos em maior detalhe. No entanto, ainda nos encontramos no domínio do soft law. Pelo que, por enquanto, urge analisar este tema à luz do direito português em vigor. 


\section{DE IURE CONDITO}

\subsection{GENERALIDADES}

Desçamos agora à esfera nacional. $\mathrm{O}$ direito interno da concorrência pouca atenção dedica à reparação dos danos causados a particulares. A Lei da Concorrência - Lei 18/2003, de 11 de Junho - não prevê qualquer mecanismo específico de responsabilidade civil, sendo que, nas palavras de Teresa Moreira $^{17}$, o regime português da concorrência "não pretende proteger os concorrentes (das empresas infractoras) mas sim preservar a Concorrência enquanto situação de mercado desejável, com vista ao Bem Estar geral" e "só indirectamente e de forma mediata beneficiará os consumidores: há normas especiais próprias para a defesa dos direitos e salvaguarda dos interesses dos consumidores, cometidas a entidades públicas distintas". Depreende-se das palavras de Teresa Moreira que as normas de direito da concorrência tutelam interesses demasiado difusos para que possam ser densificados na esfera jurídica concreta de um particular, seja ele uma empresa ou um consumidor. $O$ direito da concorrência limitar-se-ia, então a tutelar um bem jurídico mais vago, uma "situação de mercado desejável", não podendo ser invocado por um particular para defender os seus próprios interesses. $\mathrm{Na}$ verdade, al. f) do art. 44.. da Lei da Concorrência atribui relevância à reparação por parte do infractor dos danos causados à concorrência, valorando-a favoravelmente em sede de determinação da medida da coima. Ainda que se deva entender que os prejuízos aqui referidos se reportam à concorrência enquanto situação de mercado desejável, e não à esfera dos próprios concorrentes, porquê prescindir (como tem sucedido na prática em Portugal) da responsabilidade civil enquanto elemento de um quadro sancionatório mais amplo?

Porém, se por um lado esta questão se aloja no direito da concorrência e, consequentemente, não pode ser analisada sem ter em conta considerações

\footnotetext{
${ }^{17}$ Teresa Moreira, Balanço do Regime Jurídico da Concorrência em Portugal e Perspectivas Futuras, apresentação em powerpoint realizada na Faculdade de Direito da Universidade de Coimbra (CEDIPRE), em 6 de Janeiro de 2007.
}

Revista Brasileira de Direito Internacional, Curitiba, v.7, n.7, jan.jun.2008 
próprias deste ramo do direito, por outro, ela invoca questões básicas de direito civil.

Ao falar em private enforcement, referimo-nos ao recurso por parte dos particulares - concorrentes ou consumidores, por si só, colectivamente, ou através de entidades que representem os seus interesses - a uma acção de responsabilidade civil aquiliana com vista à sua compensação por danos que tenham sofrido em resultado de uma violação de regras de direito da concorrência.

Tendo ganho relevo prático e teórico nos Estados Unidos muito antes de tal suceder na Europa, é natural que toda esta matéria esteja impregnada dos conceitos próprios do direito norte-americano. Ao construir uma teoria da reparação de danos por violação do direito da concorrência em Portugal, poderá sempre recorrer-se a essa larga experiência desenvolvida nos tribunais do outro lado do Atlântico, bem como ao acquis communautaire e ao trabalho da Comissão Europeia. Porém, o quadro jurídico de base não pode ser outro senão o nosso próprio direito das obrigações.

\subsection{PRESSUPOSTOS}

Disposição fundamental neste âmbito é o art. 483. do CC. Nela se estabelecem os pressupostos que, na ausência actual de uma norma que preveja para estes casos uma responsabilidade sem culpa ou com culpa presumida, terão de ser preenchidos pelo autor: facto, ilicitude, culpa, dano e nexo de causalidade entre o facto e o dano.

Em primeiro lugar, é necessário que se verifique um facto, o qual pode consistir num acto ou numa omissão. Actos susceptíveis de atrair esta responsabilidade poderão ser, por exemplo, a realização de um acordo de concertação de preços ou a prática de factos que consubstanciem um abuso de posição dominante. Uma omissão relevante neste domínio poderá ser a não notificação de uma operação de concentração de empresas à AdC. No entanto, será que o que aqui releva é a omissão de notificar ou a acção de concentrar? A relevância de qualquer das hipóteses depende de considerações que 
teceremos quanto à ilicitude. No que toca ao presente pressuposto, nada obsta a que a omissão de notificação seja considerada um facto para efeitos de responsabilidade civil.

O segundo pressuposto é a ilicitude do facto. Seguindo a letra da lei, o facto tem que resultar na violação ilícita do direito de outrem ou de qualquer disposição legal destinada a proteger interesses alheios. A primeira hipótese parece estar afastada, uma vez que as normas de direito da concorrência não atribuem quaisquer direitos subjectivos que possam ser violados pelos infractores. Apenas assume relevo, assim, a segunda hipótese de ilicitude, ou seja, a violação de interesses legalmente protegidos.

Pires de Lima e Antunes Varela ${ }^{18}$ defendem que as normas de defesa da concorrência se incluem entre as que "tutelando certos interesses públicos, visam ao mesmo tempo proteger determinados interesses particulares". Vejamos como se aplica este raciocínio a cada uma das possíveis infracções à Lei da Concorrência.

Temos desde logo uma tripartição entre a) cartéis, b) abusos de dominação e, c) concentrações. Os dois primeiros pontos encontram-se agrupados na Secção II da Lei da Concorrência (Práticas Proibidas). Nos

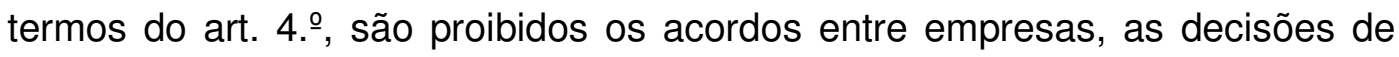
associações de empresas e as práticas concertadas entre empresas, qualquer que seja a sua forma, que tenham por objecto ou efeito impedir, falsear ou restringir a concorrência, de forma sensível, no todo ou em parte do mercado nacional. Trata-se, grosso modo, do que habitualmente se designa por cartel e corresponde à alínea a) da nossa enumeração. Os artigos 6. e 7. referem-se, respectivamente, ao abuso de posição dominante e ao abuso de dependência económica, correspondendo ambos à al. b) da nossa enumeração. Os três artigos citados partilham a mesma expressão inicial: é/são proibido(s). Isto revela que existe relativamente às práticas neles previstas um comando legal de "não fazer". Mas será o suficiente para que as consideremos ilícitas, para efeitos da aplicação do art. 483. do CC?

\footnotetext{
${ }^{18}$ Pires de Lima e Antunes Varela, Código Civil Anotado, vol. I, pp. 470 e ss., Coimbra Editora, 1997.
}

Revista Brasileira de Direito Internacional, Curitiba, v.7, n.7, jan.jun.2008 
Almeida Costa, ${ }^{19}$ distingue entre ilicitude, ou seja, violação de uma norma que impõe um dever jurídico, e ilegalidade, ou seja, violação de uma norma que apenas envolve um ónus jurídico. A consequência da primeira é uma sanção, a da segunda uma desvantagem, como, por exemplo, a invalidade do contrato de compra e venda de imóvel celebrado oralmente.

Como aplicar este raciocínio às normas acima referidas? O n. .2 do art. $4 .$. da Lei da Concorrência comina a nulidade para as práticas proibidas. Quer isto dizer que a violação das normas em questão apenas acarreta esta desvantagem e, por isso, não se considera um caso de ilicitude? Não nos parece que tal seja uma resposta correcta. Desde logo, o art. 42.. da Lei da Concorrência estabelece que as infracções às normas previstas no mesmo diploma constituem contra-ordenações e, nos termos do artigo seguinte, são punidas com coimas a aplicar pela $\mathrm{AdC}$, pelo que a nulidade não é a única consequência destas infracções. No entanto, constitui uma inversão metodológica afirmar que algo é ilícito porque é punido por lei. Assim, o argumento mais convincente a favor da ilicitude é o próprio desvalor associado a estas práticas. Este resulta da razão de ser do direito da concorrência, que existe para evitar um conjunto de práticas que se reconheceu terem efeitos nefastos na sociedade, como o aumento dos preços, o surgimento de barreiras de entrada no mercado e o bloqueio da inovação. Assim, será de concluir que a violação de normas de defesa da concorrência, pelo menos as que elencámos sob as alíneas a) e b), constitui uma situação de ilicitude e não de mera ilegalidade.

Quanto à al. c), o controlo de concentrações, há que distinguir entre i) a própria concentração, ii) o (in)cumprimento do dever de notificar a AdC (ou a Comissão Europeia) antes da realização da operação, e iii) o incumprimento das decisões destas autoridades.

Aplicando neste âmbito o critério anterior, verificamos que não existe um desvalor inerente ao simples facto de duas ou mais empresas se juntarem. Em certas economias (pense-se na Portuguesa nos anos que se seguiram ao 25 de Abril de 1974), as concentrações são, na verdade meios que levam a

\footnotetext{
${ }^{19}$ Mário Júlio de Almeida Costa, Direito das Obrigações, 9. ํㅡㄹ edição, Almedina, 2004.
}

Revista Brasileira de Direito Internacional, Curitiba, v.7, n.7, jan.jun.2008 
uma maior competitividade das empresas nacionais ${ }^{2021}$. No entanto, no sistema actual, não sendo proibidas, as concentrações estão sujeitas a controlo prévio, desde que sejam retidas no filtro que a lei criou, mediante o estabelecimento de critérios objectivos, baseados na quota de mercado e no volume de negócios do conjunto das empresas participantes. As operações que tenham de ser notificadas, em virtude da aplicação destes critérios, são depois analisadas pela AdC (ou pela Comissão Europeia), devendo ser rejeitadas as que impeçam a manutenção de uma situação de concorrência efectiva no mercado nacional (artigos 9.. e 12.ำ da Lei da Concorrência).

Quanto ao dever de notificar, este constitui uma formalidade de que depende a legalidade da operação de concentração. Assim entendido, e mantendo o critério que utilizámos acima, a notificação de uma concentração à AdC surge-nos como um ónus e não como um dever jurídico. A consequência do incumprimento da norma é a ilegalidade da operação e não a ilicitude do acto.

No que diz respeito à hipótese iii), a lei comina a nulidade de todos os negócios jurídicos celebrados em violação de decisões da AdC que "hajam: a) proibido a operação de concentração; b) imposto condições à sua realização; ou c) ordenado medidas adequadas ao restabelecimento da concorrência efectiva" (art. 41. da Lei da Concorrência). Trata-se, nos 3 casos, de situações em que a operação "não passou", ou seja, em que a AdC entendeu que da concentração resultam consequências adversas para a concorrência no mercado relevante. Se as partes no negócio, inconformadas com a decisão, decidirem avançar com a operação, a despeito da decisão proferida, parecenos que a sua conduta deve ser considerada ilícita.

O pressuposto que se segue é a culpa. Não pretendendo aqui repetir, por si só, a doutrina da culpa em sede de direito das obrigações, para aí remetemos, dado que não se nos afiguram grandes especialidades neste

\footnotetext{
${ }^{20}$ Carolina Cunha, Controlo das Concentrações de Empresas, Direito Comunitário e Direito Português, IDET, Cadernos, N. 3, Almedina, 2005, pp. 29 e ss..

${ }^{21}$ José Luís da Cruz Vilaça, Introdução à Nova Legislação da Concorrência: Vicissitudes dos Projectos de Modernização, pp. 15 a 17, in Concorrência, Estudos, Coordenação de António Goucha Soares e Maria Manuel Leitão Marques, Almedina, 2006.
}

Revista Brasileira de Direito Internacional, Curitiba, v.7, n.7, jan.jun.2008 
campo. Numa perspectiva de iure condendo, esta questão será, porém, abordada no Capítulo 3.

Apesar de termos seguido uma organização tradicional dos pressupostos da responsabilidade delitual, reconhecemos que o dano é o pressuposto mais crítico, pelo seu carácter eliminatório. Pode haver responsabilidade sem culpa e até mesmo responsabilidade sem ilicitude, mas não há responsabilidade sem dano. Da doutrina retiramos um conjunto de classificações $^{22}$, sem que, no entanto, haja a esse respeito grandes especialidades ao nível da acção por violação do direito da concorrência. Observamos apenas que, pela natureza das infracções, os danos a ressarcir serão tipicamente danos patrimoniais, presentes ou futuros (desde que determináveis), danos emergentes ou lucros cessantes e a indemnização será calculada em dinheiro, nos termos dos $n . .^{\circ}$ e 2 do art. 566..$^{\circ}$ do CC. O grande desafio encontra-se, porém, na quantificação dos danos. Esta questão, balizada por critérios jurídicos, depende, porém, em grande medida, de estudos económicos. O Código Civil manda que seja arbitrada uma indemnização correspondente à diferença entre a situação patrimonial actual do lesado e a situação patrimonial que este teria, caso não tivesse ocorrido o facto danoso. Então, para calcular esta diferença, é necessário determinar as condições do mercado caso não tivesse ocorrido a conduta anti-concorrencial e, segundo passo, qual seria a situação patrimonial do lesado nessas condições.

Por fim, temos o pressuposto do nexo de causalidade entre o facto e o dano. Abstemo-nos aqui de ter em consideração as várias correntes doutrinárias sobre o nexo de causalidade e atemo-nos à teoria da causalidade adequada, adoptada pelo CC, no seu art. 563. e pela doutrina maioritária. Esta teoria implica a realização de um juízo de prognose póstuma, segundo o qual a prática de determinado facto é, ou não, considerada adequada a originar determinado dano, devendo ser tidos em conta os contornos específicos de cada caso.

Por fim, coloca-se ainda a questão da repercussão dos danos. Esta mereceu a atenção da Comissão nos recentes Livro Branco e Livro Verde, de

22 Luís Manuel Teles de Menezes Leitão, Direito das Obrigações, Vol. I, Almedina, 2003, pp. 334 e ss..

Revista Brasileira de Direito Internacional, Curitiba, v.7, n.7, jan./jun.2008 
que falaremos no próximo Capítulo. Uma hipótese simples para exemplificar este problema: as empresas A, B e C, produtoras de azeite em Portugal, estabelecem um acordo secreto pelo qual todas aumentaram os preços do azeite em $€ x x$. D, revendedor, perante a subida do preço e a possibilidade de ver a sua margem de lucro encurtada, decide também aumentar o preço, mas apenas em $€ x$. Supondo que o próximo interveniente na cadeia é o consumidor final, quem pode ser indemnizado? Há que colocar duas questões: i) pode o infractor invocar a repercussão do dano para limitar a sua responsabilidade em relação ao primeiro comprador, quando accionado por este (passing on defense)?, e ii) pode o segundo comprador e os compradores subsequentes que ainda tenham sido afectados pelo aumento de preços pedir uma indemnização ao infractor com base nessa repercussão? A situação pode ser esquematizada com recurso ao seguinte diagrama ${ }^{23}$ :

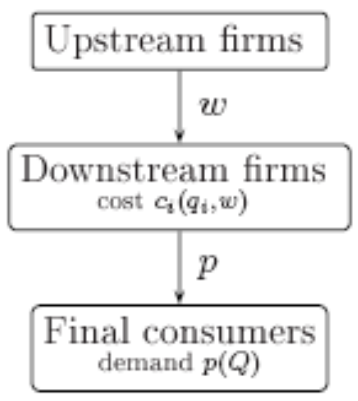

Se D intentar uma acção contra A, B e C, pedindo a reparação de um prejuízo de €nn (o que pagou a mais pelas suas mercadorias, em virtude do aumento do preço unitário em €xx) e nela demonstrar o preenchimento dos pressupostos acima referidos, estão reunidas as condições para que seja efectivamente indemnizado. No entanto, os réus poderão vir alegar que $D$ não sofreu prejuízos no valor de €nn, pois parte desse prejuízo foi transferido para o consumidor final. A base jurídica para este argumento poderá ser encontrada

\footnotetext{
${ }^{23}$ Boone, Jan and Müller, Wieland, The Distribution of Harm in Price-Fixing Cases (August 15, 2008). Center Discussion Paper Series No. 2008-68, de onde foi também copiado o diagrama reproduzido. Disponível em: http://ssrn.com/abstract=1262173
}

Revista Brasileira de Direito Internacional, Curitiba, v.7, n.7, jan./jun.2008 
no instituto do enriquecimento sem causa (arts. $473 . .^{\circ}$ e ss. do CC) ou, ainda que por analogia, na culpa do lesado (art. 570. do CC).

Por seu turno, o consumidor final poderá vir também intentar uma acção contra A, B e C, mas esta apenas será procedente na medida em que não ultrapasse a proporção em que $\mathrm{o}$ aumento de preço por parte do revendedor o afectou e não com base no aumento de preço por parte do produtor, pois parte desse aumento pode ter sido absorvido pelo revendedor, através da diminuição da sua margem de lucro.

Assim, parece-nos que ambas as questões acima indicadas devem ser respondidas positivamente. Através de um juízo de prognose póstuma podemos chegar à conclusão que o facto imputável a $A, B$ e $C$ é causa adequada dos danos sofridos por $\mathrm{D}$ e pelos consumidores finais, na proporção em que efectivamente os sofreram, pelo que só nessa medida devem ser indemnizados pelos infractores.

\subsection{SÍNTESE}

Em síntese, face ao direito constituído, cabe ao lesado preencher todos os pressupostos da responsabilidade civil extra-contratual (art. 483. do CC). É possível, face ao nosso direito, obter uma indemnização por danos sofridos em resultado de uma infracção ao direito da concorrência. No entanto, o facto de não existir experiência prática em Portugal neste domínio não se justifica apenas pela falta de "cultura litigante" que alguns alegam. Existem entraves jurídicos, do ponto de vista do direito substantivo e adjectivo que urge suplantar, designadamente, a legitimidade dos consumidores finais, o acesso aos meios de prova, a dúvida quanto ao valor probatório das decisões da AdC, a prova da culpa, o cálculo da indemnização e os custos do processo. 


\section{EVOLUÇÃO E PERSPECTIVAS. O LIVRO BRANCO SOBRE ACÇÕES DE INDEMNIZAÇÃO POR INCUMPRIMENTO DAS REGRAS COMUNITÁRIAS NO DOMÍNIO ANTITRUST}

\subsection{GENERALIDADES}

Após a publicação em 2005 do Livro Verde ${ }^{24}$ da Comissão Europeia sobre Acções de Indemnização Devido à Violação de Regras Comunitárias no Domínio Antitrust, a discussão foi recentemente relançada devido à publicação de um Livro Branco ${ }^{25}$ sobre o mesmo tópico. Mas qual o sentido e o significado deste novo documento? Que mudanças se anunciam ${ }^{26}$ ?

Uma primeira nota para o âmbito subjectivo e material da acção de indemnização preconizada pela Comissão: "todas as categorias de vítimas, e todos os tipos de incumprimento dos artigos $81 . .^{\circ}$ e $82 . .^{\circ}$ e a todos os sectores da economia" ${ }^{27}$. Ao referir-se a todas as categorias de vítimas procura incluir, com efectividade, os consumidores, e não apenas os concorrentes, nesta esfera de tutela. No entanto, ao referir-se aos artigos 81. e 82. do TCE deixa de fora o controlo de concentrações, o que, de resto, vai de encontro ao que já vimos no quadro do direito nacional, porquanto a noção de ilicitude que dá lugar à responsabilidade civil não se afigura facilmente compatível com a natureza do instituto. É de notar que ambos os documentos da Comissão se referem apenas à aplicação dos referidos artigos do TCE e não das normas

\footnotetext{
${ }^{24}$ Livro Verde - Acções de indemnização devido à violação das regras comunitárias no domínio antitrust, apresentado pela Comissão a 19.12.2005. Disponível em: http://eur-lex.europa.eu/LexUriServ/LexUriServ.do?uri=CELEX:52005DC0672:EN:NOT

${ }^{25}$ Livro Branco sobre acções de indemnização por incumprimento das regras comunitárias no domínio antitrust, apresentado pela Comissão a 02.02.2008. Disponível em: http://ec.europa.eu/comm/competition/antitrust/actionsdamages/documents.htm

${ }^{26}$ Jean Paul Jacqué, Droit Institutionnel de L'Union Européenne, 2.e édition, 2003, Paris, Dalloz, p. 512. O Autor relembra que os Livros Verdes e Livros Brancos da Comissão se contam entre os actos "hors nomenclature", ou seja actos de direito comunitário derivado que não se encontram tipificados no art. 249 do TCE. Através deles, a Comissão "recolhe a opinião das instituições e dos particulares antes de apresentar uma proposta legislativa". Estas comunicações da Comissão não produzem efeitos jurídicos, mas podem "fazer nascer uma confiança legítima na esfera dos destinatários sempre que o comportamento futuro do autor seja descrito com uma certa precisão" (tradução nossa).

${ }_{27}$ Livro Branco sobre acções de indemnização por incumprimento das regras comunitárias no domínio antitrust, p. 4. As demais citações deste capítulo sem referência pertencem também a este documento.
}

Revista Brasileira de Direito Internacional, Curitiba, v.7, n.7, jan./jun.2008 
nacionais, e que futuras medidas que sejam tomadas por via de Regulamento ou Directiva, também apenas operarão neste plano. No entanto, atendendo ao primado do direito comunitário sobre o direito nacional, deve entender-se que a aplicação das normas nacionais de defesa da concorrência deve estar alinhada com as melhores práticas comunitárias, e isso inclui, em nossa opinião, a adaptação das normas civis e processuais civis que influam no efectivo acesso dos particulares à via civil para fazer valer o direito da concorrência.

\subsection{TÓPICOS EM ANÁLISE E PROPOSTAS DA COMISSÃO}

Os dois documentos da Comissão são relativamente simétricos quanto ao seu conteúdo. Os seus temas principais são: i) o acesso aos meios de prova, ii) a culpa, iii) a indemnização, iv) a legitimidade dos compradores indirectos e a repercussão de custos por parte dos compradores directos, v) a defesa dos direitos dos consumidores, vi) o custo das acções, vii) a interacção entre as autoridades de concorrência e os particulares viii) a interacção entre os programas de clemência e as acções de indemnização, e ix) os prazos de prescrição.

Os pontos i), vii) e viii) suscitam essencialmente questões relacionadas com a prova. Por um lado, a Comissão propõe que sejam atribuídos aos tribunais poderes mais amplos para, cumpridos certos requisitos, ordenar às partes ou a terceiros que divulguem meios de prova em seu poder, bem como para impor sanções pela destruição ou recusa em apresentar provas relevantes. Parece-nos que a eficácia desta medida dependerá muito dos meios de fiscalização que sejam concedidos aos tribunais para a pôr em prática. Mas a especificidade desta área do direito coloca questões mais complexas, na medida em que é necessário articular o regime da acção de responsabilidade civil que temos vindo a tratar com o regime público de fiscalização do cumprimento do direito da concorrência e, em particular, o regime da clemência. Colocam-se aqui duas questões: a) qual o valor probatório de uma decisão da Comissão ou da AdC em processo de contra-

ordenação?; b) os autores de um pedido de clemência podem ser prejudicados 
em sede de acção de responsabilidade civil por terem apresentado provas da sua participação em actividades ilícitas?

Em nome da coerência e da segurança jurídica, a Comissão defende que uma decisão definitiva dela própria ou de uma autoridade de concorrência nacional que declare verificada uma infracção, deve constituir presunção iuris et de iure da mesma infracção em sede de acção de indemnização. A proposta da Comissão parece-nos poder implicar uma perigosa intromissão do poder executivo no poder judicial e, nessa medida, face à ordem jurídica portuguesa, de constitucionalidade duvidosa. Não nos parece aceitável que se atribua carácter irrefutável à presunção, mas já se nos afigura como compatível com o princípio da separação de poderes e da independência dos tribunais (artigo 203. da CRP) o estabelecimento de uma presunção iuris tantum. Porém, de modo a garantir a igualdade de armas, parece-nos que também a presunção iuris tantum inversa (ou seja, uma decisão que declare a não verificação de uma infracção) deve aproveitar ao réu.

Quanto à questão b), a Comissão defende, a nosso ver bem, que seja assegurada protecção às empresas que apresentem pedidos de clemência, quer o pedido seja aceite, rejeitado ou não dê lugar a qualquer decisão.

O ponto ii) refere-se à culpa. Aqui a Comissão propõe, para os sistemas em que, como o nosso, é necessário provar a culpa do infractor, que se introduza uma presunção ilidível de culpa. Trata-se de uma presunção que diríamos qualificada, uma vez que só é ilidida mediante prova de "erro verdadeiramente desculpável”. A presunção de culpa é característica da responsabilidade obrigacional, no entanto, nada impede que ela seja estabelecida para determinados casos de responsabilidade extra-obrigacional.

No que diz respeito à questão iii), a Comissão, no recente Livro Branco, começa por constatar o óbvio, ou seja, que a indemnização deve conduzir a uma reparação total do dano real sofrido pelo lesado, compreendendo esta noção quer os danos emergentes, quer os lucros cessantes e, adicionalmente, juros. Apesar de estes princípios estarem já presentes na jurisprudência comunitária, a Comissão propõe-se codificá-los sob a forma de regulamento, de modo a garantir a segurança jurídica neste âmbito.

Revista Brasileira de Direito Internacional, Curitiba, v.7, n.7, jan./jun.2008 
De seguida, a Comissão reconhece a complexidade subjacente à quantificação do dano real, a qual requer um juízo hipotético quanto às condições do mercado em questão ao tempo em que se verificou ou se iniciou a restrição da concorrência. O valor da indemnização corresponde, pois, à diferença entre o património do autor caso a restrição não tivesse ocorrido e a situação actual do património do autor. De modo a aliviar os tribunais destes complexos cálculos, a Comissão pretende estabelecer um sistema de presunções de base estatística. Para tal, findo o período de consulta pública subsequente à publicação do Livro Branco, a Comissão lançou já um concurso público para a elaboração desse método estatístico simplificado, a aplicar pelos tribunais dos Estados Membros ${ }^{28}$.

O Livro Branco optou pelo silêncio sobre a questão dos punitive damages. Relativamente a esta questão, a doutrina Portuguesa ${ }^{29}$ afirma "Está subjacente à responsabilidade civil a ideia de reparação patrimonial de um dano privado". E ainda, "O Cód. Civ. consagra basicamente a concepção clássica de que a responsabilidade civil por actos ilícitos tem a função de reparar os danos causados e não fins sancionatórios". Isto exclui a atribuição de treble damages, que são uma modalidade de punitive damages a que aludimos a propósito do ordenamento jus-concorrencial norte-americano. A questão ficaria, pois, resolvida, em sede de direito das obrigações geral. No entanto, na área do direito comunitário da concorrência, o ano de 2005 parecia querer abalar estas certezas. Como nota John Gotanda ${ }^{30}$, a par da consagração deste tipo de indemnização em certos ordenamentos jurídicos europeus, com destaque para o francês, também a Comissão Europeia, no Livro Verde, avançou com a possibilidade de a participação num cartel horizontal dar origem a uma indemnização punitiva, mediante a multiplicação por três do dano calculado. Esta hipótese não passou ao lado da doutrina

${ }^{28} \mathrm{O}$ concurso e as condições contratuais são apresentados num conjunto de documentos publicados on-line, de entre os quais: http://ec.europa.eu/dgs/competition/proposals2/2008a510_invitation.pdf http://ec.europa.eu/dgs/competition/proposals2/2008a510_tender_specifications.pdf http://ec.europa.eu/dgs/competition/proposals2/2008a510_draft_contract.pdf

${ }^{29}$ Mário Júlio de Almeida Costa, Direito das Obrigações, 9..$^{a}$ edição, Almedina, 2004, p. 477.

30 John Y. Gotanda. Charting Developments Concerning Punitive Damages: Is the Tide Changing?, Villanova University School of Law, School of Law Working Paper Series, Year 2006, Paper 65.

Revista Brasileira de Direito Internacional, Curitiba, v.7, n.7, jan./jun.2008 
portuguesa. Abel Mateus refere-a, em passant, rotulando-a de "questão mais controversa em que será fundamental ouvir a opinião dos meios judiciários."31. Terá sido o seu carácter controverso que motivou o abandono desta proposta pela Comissão no Livro Branco. Resta saber se as vantagens desta medida não justificarão um passo em frente. O argumento do enriquecimento sem causa, que é esgrimido em seu desfavor parece lógico: quem sofreu danos de $\mathrm{x}$ não deve receber uma indemnização de $\mathrm{x}+\mathrm{y}$, pois a fracção y é injustificada do ponto de vista jurídico. No entanto, não será de considerar que existe aqui uma "causa" que, não sendo estritamente jurídica, é uma causa social: o incentivo para os particulares fazerem valer os seus direitos e a dissuasão de infractores latentes?

O carácter automático da triplicação no sistema americano é criticado ${ }^{32}$ e, de facto, este pode levar a resultados perversos. Afigura-se-nos, pois, que deveria ser preferida uma solução taylor-made em que seja possível a majoração da indemnização em função de critérios como a gravidade da conduta e o eventual desfasamento entre os ganhos e os custos da infracção para o réu (caso a indemnização apenas contemplasse danos simples). Estes critérios podem apoiar-se, na medida em que a analogia de situações o justifique, nos critérios de determinação da medida das coimas aplicáveis pela AdC, consagrados na Lei da Concorrência. Assim se evitaria a rigidez do sistema americano, sem lançar os juizes num casuísmo arbitrário. Com o tempo, a jurisprudência desenvolver-se-ia, podendo então fornecer bases estáveis aos julgadores de cada caso concreto (lembre-se, por exemplo, a abundante jurisprudência sobre o quantitativo das indemnizações por danos não patrimoniais).

A problemática subjacente ao ponto iv) já foi acima tratada, quando abordámos o problema da repercussão dos danos (Cap. 2). Face ao texto do Livro Branco, não restam dúvidas quanto à legitimidade dos compradores indirectos (muitas vezes, consumidores) para proporem acções por danos, nem

\footnotetext{
${ }^{31}$ Abel M. Mateus, Sobre os Fundamentos do Direito e Economia da Concorrência, Revista da Ordem dos Advogados, Ano 66, Vol.. III - Dez. 2006.

${ }^{32}$ P.J. Wills, The Optimal Enforcement of EC Antitrust Law, Chapter 2.2.3., Essays in Law and Economics, Kluwer Law International, 2002, The Hague, London, New York.
}

Revista Brasileira de Direito Internacional, Curitiba, v.7, n.7, jan./jun.2008 
quanto à admissibilidade da passing on defense (respostas que preconizámos acima). No entanto, para que possamos testemunhar um efectivo recurso aos tribunais por parte dos consumidores, dois "mecanismos colectivos" são propostos: as acções representativas e as acções colectivas por adesão. $O$ elemento distintivo entre as duas é a iniciativa. Se as primeiras decorrem da iniciativa de uma entidade qualificada, as segundas resultam da agregação de pedidos individuais.

No CPC encontramos duas figuras afins a estas acções colectivas propostas pela Comissão. Referimo-nos ao litisconsórcio e à acção popular, previstas, respectivamente, nos artigos 27. e 26-A. Enquanto a acção popular mostra alguns elementos comuns à primeira modalidade, o litisconsórcio pode servir de base jurídica para a implementação da segunda modalidade. Assim, estas propostas da Comissão não encontram em Portugal terreno vazio, existindo já regimes que podem ser adaptados e aperfeiçoados, tendo em conta as especificidades do direito da concorrência.

As propostas da Comissão sobre o modo de contar os prazos prescricionais (apenas a partir da cessação da infracção, ou a partir do momento em que o lesado teve conhecimento da infracção ou do dano) não colidem com a lei portuguesa, pelo que não nos suscitam mais comentários.

Por fim, a recomendação no sentido de os Estados aligeirarem as custas judiciais nestes casos justifica-se principalmente no que toca às acções intentadas por consumidores, em que a "situação financeira [do autor] for significativamente menos sólida que a do requerido".

Como é evidente, nenhuma das medidas aqui referidas terá o mínimo de utilidade se os juizes não receberem formação adequada nestas matérias. Uma hipótese a considerar é a intervenção da AdC enquanto consultora, partilhando os seus conhecimentos e experiência com os tribunais civis, o que, à falta de melhor base jurídica, poderá ocorrer no âmbito da prova pericial. 


\section{CONCLUSÕES}

Procurámos até agora analisar a questão do ressarcimento de danos resultantes de infracções ao direito da concorrência. Coloquemos, pois, à prova o que dissemos através de um pequeno caso prático.

Imaginemos que o Sr. A, empresário em nome individual, cuja actividade profissional consiste na venda de artigos de mercearia, frutas e legumes ao domicílio, verificou que o seu negócio, que até ao início de 2008 considerava marginalmente rentável, passou a dar origem a prejuízos. O Sr. A considera que tal se deve, por um lado, ao aumento do preço do gasóleo, de que depende diariamente para alimentar a sua frota de 3 carrinhas, e por outro, ao aumento do preço dos próprios produtos distribuídos. Tendo em conta a sua área de actuação geográfica e social (principalmente idosos e donas de casa em várias localidades do interior do país), o Sr. A. está convicto de que se aumentar os preços que ele próprio pratica de modo a compensar o aumento dos custos, tal resultará numa diminuição do volume de vendas.

Depois de ter ouvido no noticiário que estes aumentos de preços podem estar ligados a uma conduta ilícita por parte das petrolíferas, o Sr. A. decide procurar um advogado, dizendo-lhe que quer "pôr em tribunal" as petrolíferas $B, C$ e $D$ para ser indemnizado pelos prejuízos que teve durante este ano. $O$ advogado diz-lhe que, tanto quanto sabe, nunca ninguém pediu tal coisa em tribunal algum em Portugal e que, por isso, o risco de não recuperar o investimento é grande. Diz-lhe ainda que precisa de uma provisão para pagar a taxa de justiça inicial, que é calculada com base no valor da aç̧ão, ou seja, a quantificação dos danos feita pelo contabilista. Afirma que a subida dos preços dos combustíveis também o afectou e que não se importaria de avançar com a acção e de fazer contas no fim, conforme fosse o resultado do trabalho, mas que não o pode fazer, sob pena de vir a ter problemas com a Ordem dos Advogados. Por isso, o cálculo dos honorários terá que ser feito com base numa taxa horária.

O Sr. A aceita e o advogado começa a trabalhar na acção. Durante o seu trabalho, conclui que:

Revista Brasileira de Direito Internacional, Curitiba, v.7, n.7, jan.jun.2008 
1. O meio adequado é uma acção declarativa de condenação com base no regime da responsabilidade civil extra-contratual (art. $483 .^{\circ}$ do $\mathrm{CC})$.

2. Na petição inicial tem que alegar e oferecer provas: i) do dano; ii) da prática de um facto ilícito por parte das rés; iii) da culpa das rés; e iv) do nexo de causalidade entre o facto e o dano.

3. De acordo com as suas investigações, a Comissão Europeia recomenda que sejam feitos estudos económicos para facilitar a quantificação dos danos (não que o advogado não confie no contabilista do Sr. A, claro!) e que se facilite a prova da culpa, através da criação de uma presunção como a que existe para a responsabilidade contratual. No entanto, em Portugal, nada foi ainda feito nesse sentido.

4. Para preencher o pressuposto da ilicitude, teve de ir estudar as leis da concorrência e decidiu utilizar dois fundamentos cumulativos: a) o abuso de posição dominante colectiva por parte das 3 rés; e b) a concertação de preços entre as 3 rés.

5. Encontrou no site da $\mathrm{AdC}$ um recente relatório sobre o mercado dos combustíveis em Portugal ${ }^{33}$, em que é negada a existência das condutas ilícitas que decidiu alegar. Mas não desanimou, afinal ainda não foi tomada posição em Portugal sobre a relação entre as decisões da $\mathrm{AdC}$ e as acções de carácter civil. Para além disso, nem sequer se trata aqui de uma decisão, mas de um relatório, pelo que, aproveitou o documento para estruturar a sua argumentação e continuou o trabalho.

6. Ao chegar à última página, deparou-se com a necessidade de formular o pedido em termos numéricos. Baseou-se nas informações transmitidas pelo contabilista, uma vez que não encontrou qualquer estudo sobre os métodos de quantificação deste tipo de danos.

7. De acordo com as informações de que dispõe, o Sr. A. não aumentou o preço de venda ao público dos seus produtos. Assim, as rés não poderão vir utilizar a chamada passing on defense para reduzir o montante da indemnização.

8. Para além disso, ao abrigo do nosso direito, a responsabilidade civil visa unicamente ressarcir danos, ou seja, repor a situação

${ }^{33}$ http://www.concorrencia.pt/download/AdC_Relatorio_Petroliferas_02-06-2008.pdf

Revista Brasileira de Direito Internacional, Curitiba, v.7, n.7, jan./jun.2008 
existente antes da verificação do facto danoso. Consequentemente, não parece provável que venham a ser, num futuro próximo, atribuídas indemnizações de carácter punitivo pelos tribunais portugueses.

9. Por fim, como sempre, passou à "juntadas": procuração, "docs" e comprovativo do pagamento da taxa de justiça inicial. Olhou para os documentos que acabara de numerar e verificou que tinha balancetes, talões das bombas de gasolina, facturas e recibos. Todos provavam claramente que o Sr. A sofrera danos em resultado da subida do preço dos combustíveis. Porém, faltavam documentos ou outras provas sugestivas da conduta ilícita das rés. Estes, se existirem, estão na posse das próprias e, apesar da recomendação da Comissão nesse sentido, não existem ainda mecanismos que facilitem a obtenção de provas por parte dos autores deste tipo de acções (tirando, eventualmente, a realização de uma inspecção judicial, mas o advogado acha pouco provável que o juiz venha a encontrar nas instalações das petrolíferas algum vestígio da infracção - como naquela conhecida história em que as actas das reuniões de um cartel alemão estavam organizadas em dossiers numerados com etiquetas que diziam "reunião do cartel").

O advogado enviou a P.I. para o tribunal do domicílio do Réu e ficou à espera de resposta. O Sr. A pode não ter razão. Não tomamos qualquer posição quanto a esse ponto. No entanto, as dificuldades que tentámos exemplificar parecem-nos castradoras do acesso privado à justiça. Não pretendemos, tampouco, fazer uma importação automática das soluções norteamericanas, nem promover uma litigiosidade exacerbada, pois estamos conscientes dos custos que isso teria para o país. Porém, o private enforcement, para além das vantagens que já lhe apontámos, permitiria um maior envolvimento dos cidadãos na justiça. Na verdade, não apenas no que diz respeito ao direito da concorrência, mas também num conjunto de outros domínios, como o da corrupção, é usual ouvir críticas à inacção das autoridades. Ora, concedam-se meios aos particulares e esperemos que se faça justiça. 


\section{REFERÊNCIAS}

Douglass C. North, John Joseph Wallis, Barry R. Weingast, The Natural State: The Political-Economy Of Non-Development, March 2005. Texto integral disponível em:

http://www.fnf.org.ph/downloadables/Douglass\%20North\%20Article.pdf

António Goucha Soares e Maria Manuel Leitão Marques, Concorrência Estudos, Almedina, 2006.

Richard A. Posner, Antitrust Law, Second Edition, The University of Chicago Press, Chicago and London.

Kevin E. Grady, Lessons learned from the US experience in private enforcement of competition law, Handbook of Research in Trans-Atlantic Antitrust, Edward Elgar, 2006.

Comments of the Section of Antitrust Law and the Section of International Law of the American Bar Association in Response to the Request for Public Comment of the Commission of the European Communities On Damage Actions for Breaches of EU Antitrust Rules, April 2006, p. 4. Texto disponível em:

http://ec.europa.eu/comm/competition/antitrust/actionsdamages/files_green_pa per_comments/aba.pdf

Richard Whish, Competition Law, Fifth Edition, LexisNexis, UK.

Teresa Moreira, Balanço do Regime Jurídico da Concorrência em Portugal e Perspectivas Futuras, apresentação em powerpoint realizada na Faculdade de Direito da Universidade de Coimbra (CEDIPRE), em 6 de Janeiro de 2007.

Pires de Lima e Antunes Varela, Código Civil Anotado, vol. I, pp. 470 e ss., Coimbra Editora, 1997.

Mário Júlio de Almeida Costa, Direito das Obrigações, 9. edição, Almedina, 2004.

Carolina Cunha, Controlo das Concentrações de Empresas, Direito Comunitário e Direito Português, IDET, Cadernos, N.ํㅜ 3, Almedina, 2005.

Luís Manuel Teles de Menezes Leitão, Direito das Obrigações, Vol. I, Almedina, 2003.

Boone, Jan and Müller, Wieland, The Distribution of Harm in Price-Fixing Cases (August 15, 2008). Center Discussion Paper Series No. 2008-68Disponível em: http://ssrn.com/abstract=1262173 
Jean Paul Jacqué, Droit Institutionnel de L'Union Européenne, 2.e édition, 2003, Paris, Dalloz.

Mário Júlio de Almeida Costa, Direito das Obrigações, 9. a edição, Almedina, 2004.

John Y. Gotanda. Charting Developments Concerning Punitive Damages: Is the Tide Changing?, Villanova University School of Law, School of Law Working Paper Series, Year 2006, Paper 65.

Abel M. Mateus, Sobre os Fundamentos do Direito e Economia da Concorrência, Revista da Ordem dos Advogados, Ano 66, Vol.. III - Dez. 2006.

P.J. Wills, The Optimal Enforcement of EC Antitrust Law, Chapter 2.2.3., Essays in Law and Economics, Kluwer Law International, 2002, The Hague, London, New York. 